\title{
J
}

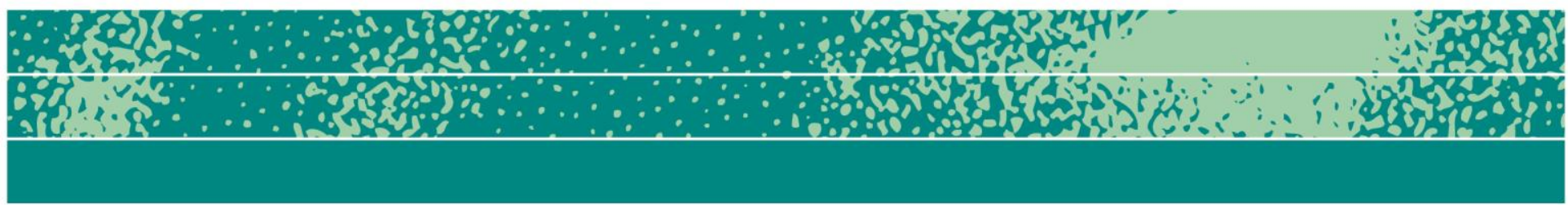

\section{Liminality in Advertising from the Mad Men Era}

Barbara Olsen

\begin{abstract}
This article reflects an evolving anthropologist's marketing career during the 1970s, before anthropology was truly welcomed as contributor to business strategy. I worked on several accounts mentored by a brilliant but conflicted creative director-guru-boss, an experience resulting in this reflexive advertising narrative punctuated by periods of liminality. I used my agency archives from the 1970s and field notes (or advertising log) as my data set to reflect this period. My field journey traversed the Mad Men era, immortalized in the AMC TV series about the 1960s and beyond, where creative directors freely crossed boundaries of sex, class and gender stereotypes. I discuss several advertising campaigns in which I was involved. The broader narrative reveals an uncomfortable divide between cultural empathy and advertising practice. While creatively stimulating, I describe the conflict in a marketing career that challenged ethical sensitivities.
\end{abstract}

Page 1 of 28

JBA Special Issue 2: 77-104, Spring 2016

(c) The Author(s) 2016 ISSN 2245-4217

www.cbs.dk/jba

\section{Keywords}

Advertising history, anthropology, liminality, reflexivity 


\section{Prologue}

It was fall 1972; I was back in New York after a divorce wondering what my next career move would be. A friend suggested I give Adam Wilson a call. We had known him since the 1960s when I was a freelance illustrator attending Hunter College in their graduate anthropology program. I decided to visit his ad agency on Madison Avenue since I heard it was hiring.

On the day of my appointment, I sat down and waited an hour. Finally, I was called into the office and Adam Wilson, the Creative Director and owner of the small advertising and promotion firm, rose from his desk and shook my hand. He said, "What brings you here?" I responded, "I'm looking for a job. No more freelance. I want to work full time." He sat down, folded his hands over the vest of his dark blue three-piece suit. The chain of his gold watch fob dangled to its pocket. I held my breath. After a long pause he said, "I can't hire you. I'd only want to make you my girlfriend."

No, this is not a clip from the contemporary TV show Mad Men, which I honestly find too painful to watch because of the similarity with my ad career. This conversation actually happened. I countered with a lecture on the unfairness of his response. Wilson backed down and said, "It was a joke." But, it was not. The Adam Wilson \& Friends agency was located in the penthouse suite of a building on Madison Avenue and 54th Street in Manhattan. The elevator opened into a gray-carpeted waiting room. The design of the entire office was classic Bauhaus modern, simple yet elegant. Two receptionists sat at desks along the wall leading to the back offices of account executives, copywriters and art director. The "bull pen"-a room where concepts were rendered into finished mechanicals (ad layouts ready for engraving) - was at the end of the corridor. Nearby, Wilson's office featured a black desk similar to the long black table in the conference room next door. Degrees from Cooper Union and Yale hung on the white wall next to a painting, a grey "Homage to the Square" by Richard Anuszkiewicz. As I studied the painting, he explained that at Yale they were both students of Josef Albers, well known for his nested squares of color. Albers himself studied at the Bauhaus school in Europe, where design was predicated on utilitarian elegance.

Adam reminded me of Napoleon-short and stocky, confident and commanding. We said we would talk in the next week and I left feeling dejected. The song, "Watching and Waiting for a Friend to Play With" by the Moody Blues, from their album To Our Children's Children, played on my emotional jukebox as I entertained the possibilities during my return trip home. Yes, I took the job and the opportunity to be mentored by a creative director who became my new friend. It was the beginning of a mutually beneficial relationship that transformed into a platonic friendship and a long-term business partnership. For the next sixteen years I worked with him and went to school learning both advertising and 
anthropology, enriched by both.

Adam's offer was the answer to my dilemma. He championed my need for economic independence and introduced me to the city's museums that became our weekend outings. I took classes at the Art Students' League and enrolled in the School of Visual Arts to perfect my skills at work. In spring 1973, I decided to finish my degrees in anthropology at The New School of Social Research in New York. By 1977, the personal relationship became too complicated and we resolved to be friends and business partners. My next significant other occasionally made a contribution to Wilson's team. On the surface we appeared to make "\& Friends" a reality.

My reflexive narrative of liminality, that is being "betwixt and between" as described by Turner (1979:236-237), covers my sense of ambiguity with advertising in the 1970s. Toward this end, I here review my collection of Adam Wilson \& Friends' advertising archives, focusing on three marketing campaigns I worked on in various capacities between 1972 and 1980. At first, I loved the excitement and creativity of advertising, eventually advancing from artist to account assistant and executive responsible for several clients. However, it was also a time when anthropological reasoning was struggling to find its voice in the chatter of advertising; I often found that anthropological insight was unappreciated. By 1979, because of internal strife and an unbalanced client roster heavy with competing companies, the agency split accounts and solved my protracted state of liminality. I founded IMC Marketing Group, Ltd. to accommodate half of our clients and to have greater autonomy while completing my degree. I continued working with Adam as IMC's creative director through 1988 and leveraged my corporate position for time to finish fieldwork and complete my $\mathrm{PhD}$. That was the end of the Mad Men era for me. This phrase has become a cliché for midtwentieth century advertising, but it defies time and instead describes actual personalities and brilliant minds caught up in hubris and greed clinging to a memory of what could have been. I tried to change Adam, to add some happiness to his manic life. By the mid-1970s he confessed to having a mote around his heart. Ironically, he passed away in 2007 from an infection in fluid that had collected around his heart.

This article has relevance for practicing anthropologists as they often encounter similar work environments and emotional tension satisfying client requests. I focus on how advertising values conflicted with my anthropologically informed consciousness. I repeatedly experienced multiple phases of cognitive dissonance with varying degrees of intensity over the decade, each time cast into a liminal zone of separation, transition and incorporation (Schouten 1991; Turner 1979) with new understanding to cope with conflict, determined to survive a dysfunctional environment. The anthropological lens on culture helped me understand my liminality. I clashed with superiors over corporate 
direction, personnel issues, ad strategy, and the recollection of client discussions, which I noted in my log to preserve sanity. As described later, rifts over gender and cultural issues created cognitive dissonance with Adam's creative direction for clients in the 1970s: Warner's Bra from 1972-1975 (positioning bras in the context of women's sexual liberation); Franklin Society Federal Savings and Loan Association bank from 19751977 (teaching women financial security); and ABC Pictures International 1979-1980 (integrating cross-cultural acculturation). Each is presented as a case below, with interpretation reserved for the discussion section. In the following sections, I contextualize the concept of liminality, before proceeding to the methodology, three campaign cases, discussion-lessons for practice, and conclusion.

\section{Understanding Liminality}

Turner provides analysis for those in the pre-modern process of formal transition between social roles and status changes as they experience "the liminal period" of "betwixt and between" (1979:236-237). He follows van Gennep's original treatise (1960) demarking the rites of passage primarily aiding tribal passage from youth to adulthood in stages from "separation, [to] margin (or limen) and [to] aggregation" sequentially managing detachment, disruption and social reconnection with new requisite roles and responsibilities (Turner 1979:235).

More recently, scholars investigating contemporary liminality reveal similarities with pre-modern cousins. For instance, based on van Gennep's rites of passage (1960) and Turner's concept of liminality (1969), Schouten (1991) offers clarity for contemporary liminal status change that often incorporates rituals using consumer goods for identity reconstruction to enhance the process of formally passing from one role to another (youth to adult, married to divorced, employed to retired). He notes the familiar process: "1) separation, in which a person disengages from a social role or status, 2) transition, in which the person adapts and changes to fit new roles, and 3) incorporation, in which the person integrates the new role or status into the self." In the process, Schouten claims we engage in "identity play" with props to practice new roles (pp.49-50). His work on liminality presaged a new line of "identity project" inquiry that now informs Consumer Culture Theory (Arnould and Thompson 2005). Liminality research in corporations, however, suggests that modern rites of passage (between states of being) are more complicated and prolonged than those in pre-modern societies. Tempest and Starkey (2004) analyze the liminal dilemma of temporary contract work. Beech (2011) focuses on liminality concerning anticipated, but unfulfilled promotion and part-time status within firms. This type of liminality is familiar for practicing anthropologists between project contracts and for artists working freelance. Because I experienced liminality as cognitive dissonance while working in advertising, I will use 
the two terms interchangeably throughout the article.

To appreciate the effects of liminality, Malefyt and Morais (2012) mention that it is experienced subjectively-often with regard to a place. I experienced my liminality in an advertising agency dealing with creative direction and positioning logic for three campaigns that conflicted with the history of ideas and progressive values I was learning at the time in graduate school. "Thus, acute awareness over thoughts and feelings, ideas and realities due to interaction of place with our existing thoughts from somewhere else can result in states of confusion or indeterminacy in our thinking" (p.79). To ameliorate recurring cognitive dissonance dealing with the campaigns' positioning concepts and managerial intimidation, each time I disengaged by entering a liminal zone. Each passage began with separation (consciously aware of myself as Other with different opinions), through transition (learning various survival strategies to preserve my integrity against ridicule) and finally, to incorporation with a new sense of a stronger self (each incorporation renewed my resolve to complete the Ph.D. in preparation for the next chapter in my life). With each passage I learned new tactics to manage conflict elaborated later in lessons from the log. I recorded these moments of introspection for reflexive strategic analysis. Writing and drawing introspectively in a log while experiencing the passage significantly enhances the liminal process. Using this creative process reframes one's perception of events from incomprehensible and depressing to be able to see opportunity and new possibilities.

In liminality, by perceiving one's self as Other, we gain a heightened awareness of our social relationships and surroundings to interpret the cognitive dissonance. I became aware how the creative director appropriated cultural trends for campaign themes. Hackley (2002:214) claims that, "the advertising industry with its skill in gathering and interpreting consumer cultural knowledge [uses it] in order to fashion culturally resonant advertising." I understood that this appropriation has ideological consequences for a consumer culture where advertising exists in a feedback loop influencing social values. This echoed in my concern with our agency's campaign themes that co-opted social movements and popular culture to sell products pairing the sexual revolution and feminist beliefs in women's lib with paternalism, while also negating cross-cultural experiences with parochial norms. The level of creativity is how an agency earns its reputation. As a campaign theme evolves into ads and sales promotions, the creative concept is fueled by many voices along the way: agency director, account executive, account supervisor, creative director, copy writer, art director, and even the client. Each contributes his/her part to the cultural resonance that frames the Big Idea. As I became increasingly "entangled" in interacting with these "things" that connected us together (Hodder 2012), introspection with a log became the most valuable tool for reflection. 


\section{Methodology: Agency archive analysis and ethnographic journaling}

When Adam Wilson \& Friends split accounts in late 1979, I founded IMC Marketing Group. To create my portfolio, I took copies of the campaigns on which I had worked. For my reflection, I use these archives to deconstruct the mores of historical contexts reflected by the creative direction in three clients' advertising and sales promotion campaigns. With each campaign, I struggled to reconcile my evolving feminist values with sexist, classist, and cultural stereotyping prevalent in the industry. One way of analyzing this dissonance is through the lens of liminality parsed in the discussion.

I also maintained journals (1972-1988) in an advertising log that became my participant-observation field notes with personal reflections used to track client projects, agency meetings, and my state of mind. Between crises and chaos, these logs kept me centered. Using selfreflexivity, the log primarily informs my narrative ethnography. There are fourteen journals from 1972 to 1980 . The 1972 journal covers transitioning back to New York. Subsequent log entries in the 1970s decade included work to-do lists, class assignments, poems, essays and drawings to understand power relationships. There are many drawings depicting anxiety, cityscapes and self-portraits. The log with advertising practices and agency observations provides insight coinciding with the Mad Men era on Madison Avenue. By the 1980s, my notes are more complex with client-focused verbatims revealing provocative observations of agency power dynamics. Over time, the log became a valuable tool used to record client meetings, and reflected managerial mores that were historically contextualized and often antithetical to an anthropological way of thinking. The journals reveal liminal insight on the profound divide between Adam's managerial style and my anthropological appeal for humanity. Many times I was caught "betwixt and between" in a liminal zone (Turner 1979) of confusion wanting to quit, yet needing to work and not let my friend down. In Kaminsky's introduction to Remembered Lives, he notes that Myerhoff's recollection of the anthropological journal as a genre for "text production is described as a potential healing process, a quest for wholeness of being, for recuperating parts of the personality that are suppressed or damaged in social relations that subordinate women and induce alienation generally" (Kaminsky [in Myerhoff] 1992:84).

Marcus and Fischer (1986:113) suggest ethnographers follow a "trend that we call repatriation" to turn our focus back home. My advertising narrative using journal notes reflexively thus falls within their "experimental moment" (ibid. pp. 165, 166). Following their lead, I explore "historical and cultural conditions for the articulation and implementation of different values" (ibid. p. 167) embedded in advertising during a particular point in time. The 1960s represented a 
socio-cultural crossroads where class, gender and ethnic stereotypes were questioned. Women were encouraged to gain an education and find employment. Sexuality was liberated by the birth control pill and promoted by media, including Cosmopolitan magazine. The civil rights movement celebrated cultural and racial diversity. All were reflected in advertising's "creative revolution" during the 1960s (Cracknell 2011:21314). Creative directors began sourcing cultural trends to position the "Big Idea" (Maas 2012:136). These sentiments trickled through our agency, too, but with greater emphasis on pushing sexuality to the edge of decorum, while also honoring traditional gender roles. The result for me was embarrassment and confusion. Contestation was met with hostility. In the following section, I present the three advertising and promotion campaigns for Warner's Bra, Franklin Society Federal Savings and Loan Association, and Touch of Home ${ }^{\mathrm{TM}}$ from ABC's Video Sales Division, while reserving my critique and introspective analysis for the Discussion section.

\section{Liminality in advertising: campaign cases from the Mad Men era}

\section{2: Consumer choice: Warner's Bra}

Before I joined Adam Wilson \& Friends, Warner's came to the agency for trade ads and sales promotion to raise its market share. In the late 1960s, Warner's share of the market lingered at eight in the bra category, well behind Playtex, Maidenform and other frontrunners. It had a serious image problem among younger females not interested in wellconstructed foundation garments targeted to their mothers' generation. The traditional Warner's customer was the older, full-figured woman whose numbers were being eclipsed by the baby boomer generation preferring a more natural look. As creative director, Adam's first solution was to brand a new bra with the name Love Touch. It was a sexy lacy bra made from softer double-knit fibers also used in the Body Crème and Comfort Curve (c. 1971) bras specifically designed for younger women. Regardless of this targeting effort, Warner's share stayed the same.

We sensed we had a sales rather than a product problem. Early on, during a discussion with the client in our office, I suggested using participant observation in stores to study "the underwear clan of the fashion tribe." My jargon was not well received. With a severe glance and eyes rolling, Adam kicked me under the table and told me later to keep my anthropology to myself. A few months later Adam asked a couple of us to watch how bras were sold in Macy's and Gimbels (upscale department stores). As far as I knew, we did not have store permission for the visit. Today, we call such observers "mystery shoppers." I was satisfied that we were conducting in-store participant observation. We encountered overwhelming frustration finding clerks for help. In upscale department stores in the early 1970s, bras were too sexy to be seen in public and were kept hidden behind the counters in drawers. A clerk produced the 
bra size and her own favorite brand or, if specified, the customer's requested brand. After the account executives reported to Adam, converting the clerks to Warner's brands became the goal to increase sales.

With Adam in the lead, during 1971, the agency created sales promotions directed at ambivalent clerks to convince them to retrieve a Warner's bra for customers to buy. Some promotions were designed so that clerks could engage a customer's attention while highlighting Warner's concern for their love life. Other promotions were presents to clerks to make their lives more cheerful. For consumers, the New Year's promotion featured astrology charts, so clerks could read a customer's horoscope. For Valentine's Day, we created a palm reading kit, "Warner's Love is in the Palm of Your Hand," so that clerks could focus customers' attention on Warner's brand while reading their love lines. This was accomplished using a transparent acetate diagram, with copy implying that Warner's Love Touch helped predict the future, placed over a customer's palm. During February, the clerk also gave each customer a booklet offering advice on " 50 ways to please your lover." The booklet offered tips on how to properly compliment your lover, how to massage and pamper him. Adam said it targeted the younger "Cosmo girl" who read Cosmopolitan magazine for advice to keep her man happy. Warner's also sent store clerks birthday greetings and Easter flowers in the top markets where Warner's was sold. For December, we created a booklet of Warner's recipes-"Guide to holiday shortcuts for tired salesgirls"-that would help clerks ("girls!") make better holiday dishes for parties. "Girls" was the typical term for female store clerks and product buyers. The Guide noted, "It's all from Love Touch ${ }^{\mathrm{TM}}$ the great new Doublelknit bra from Warner's. Happy Holiday." Unfortunately, none of these efforts increased sales at the six "upstairs" stores across the country where Warner's was sold. Ultimately, Warner's increased the advertising budget and the agency produced two print ads for Sunday newspapers and national magazines. The most sensuous ad said: "Indulge yourself in Warner's. No matter what goes on outside, you feel like more of a woman with Warner's underneath." Adam was repositioning Warner's image from old fashioned to youthful, sexy and erotic while challenging Maidenform's ads that depicted bras worn as outer garments.

Finally, our staff visited Warner's showroom and saw how store buyers chose product for the following season from rows of bras hung on hangers. It was insightful. Adam conceived a counter stand that he coined the "Money Tree" and designed it with arms to hold bras on hangers. It became a revolutionary solution that moved bras out of the drawers into public view; the same way bras were sold to the trade (wholesalers and retailers) in Warner's showroom. While Warner's vice-president thought it was a good counteract to Playtex's packaging appeal, most male management at Warner's thought it was in poor taste. We conducted a test with the stand and the bras sold out quickly. The Money Tree was 
redesigned as a floor stand. Adam's point-of-purchase innovation was the first retail self-service device for the bra lingerie category. Warner's eventually moved from eight to number two share of the bra market (Olsen 2003). After introducing Warner's Money Tree to retailers, we discovered competitors using it, too. Our next trade ad said, "Take it from Warner's, everyone else is." Adam Wilson \& Friends became the go-to agency for creative solutions. The print ad campaign and bra stand dramatically boosted sales. By 1973, working with a production company, Adam created four TV commercials that ran in the largest cities where Warner's was sold. This case represents the potential of marketing as a force for cultural change (Olsen 2003). Adam Wilson \& Friends helped revolutionize how bras were sold on public display ultimately facilitating competition while enhancing consumer choice.

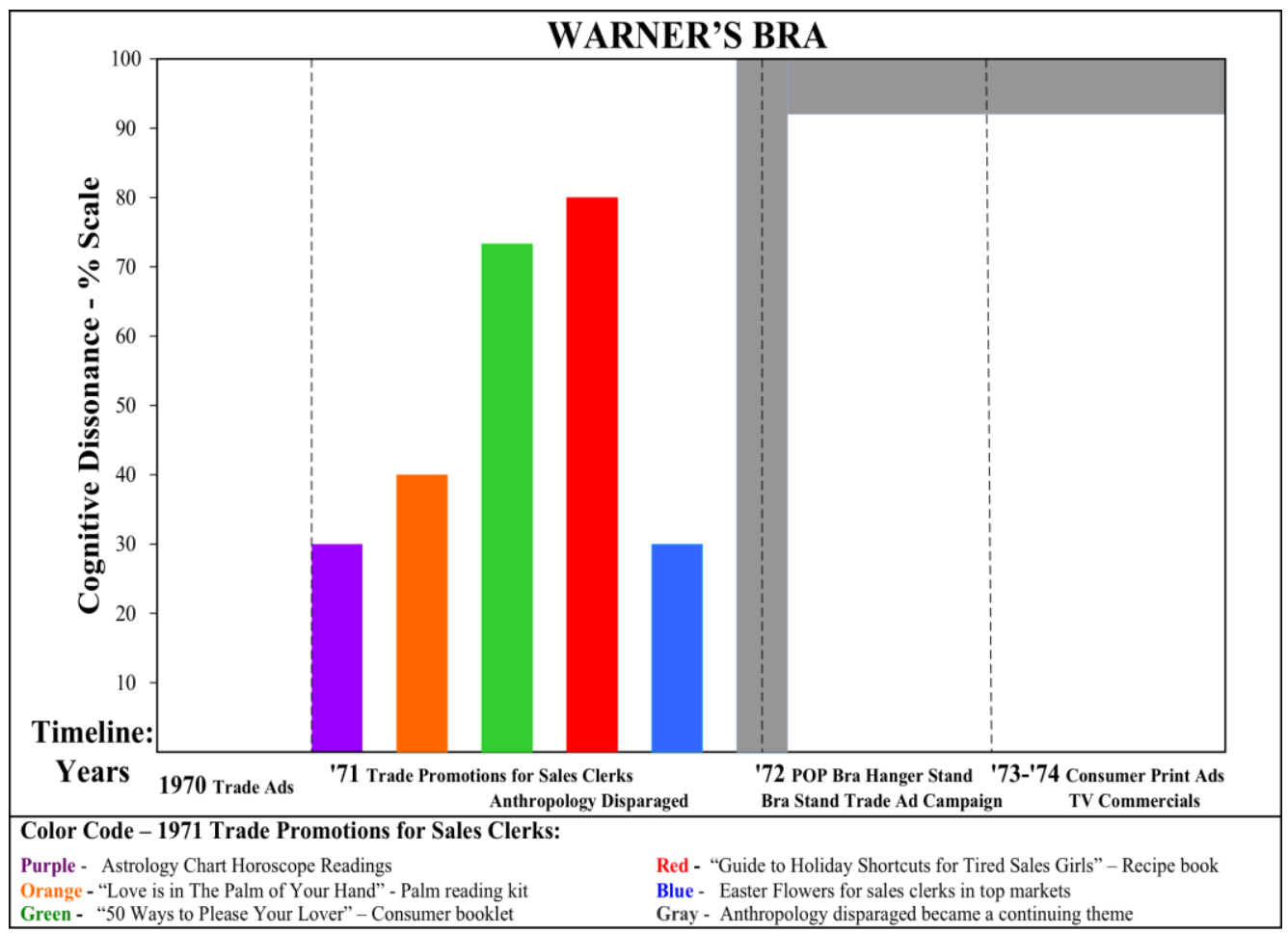

Figure 1: Changes in author's cognitive dissonance during Warner's Bra Campaign

At the same time, I had problems with the promotions (see Figure 1). The Warner's graph describes their year-round sales promotion campaign that, to my mind, objectified women and sexualized the product in an unseemly way. Store clerks received a different promotion each holiday to engage with potential customers while they decided which bra to buy. The colored bars represent my escalating discomfort (cognitive dissonance) every time I discussed this campaign.

With recognition and buzz on Madison Avenue, our agency was 
ready to grow. Marketing was exciting, I thought Adam was brilliant and I was hooked! At night I took classes at Parsons in copywriting, and at The Art Students League and School of Visual Arts in illustration, while continuing anthropology at the Graduate Faculty of the New School for Social Research (1973-1988).

\section{5: Paternalism: Franklin Society Federal Savings \& Loan Association}

In a conversation I had with Adam before his death, he confessed that I was the model for his Franklin bank campaign. I was part of a growing cohort of young feminists redefining marriage and motherhood, clueless about investing and in need of financial advice.

When the agency acquired the account for Franklin Society Federal Savings and Loan Association in 1975 their main competition was Irving Bank. Irving promoted a personal banker in their ads that concluded with "Call Irving." However, our research found no one named Irving, or any personal banker to speak with, in their branches. To counter their campaign, Adam's creative solution was "The Answer Man" for each Franklin branch. Franklin's target was retirees and women. The strategy included sales promotions and an ad campaign. The in-bank promotion included a series of educational booklets placed in a stand on bank counters to prompt discussion and initiate savings accounts. Each title helped women toward financial independence: $A$ Woman's Guide to Money; A Woman's Guide to Home Repairs; How to Shop More Wisely; How Sewing Can Save You Money; How to Make Your Husband Rich; How a Single Girl Can Save a Little Money. All advised talking to the Answer Man about opening a savings account.

Adam did not realize how objectionable this paternalistic approach was to progressive minded women of the 1970s like me. As a fledgling account assistant, I counseled against this approach (see Figure 2). The graph describes our agency's solution to attract new depositors for Franklin's savings accounts by offering relationship-building Self-Help Booklets and an ad campaign. The graph demonstrates my heightened dissonance with the creative concept that positioned women in need of a man or needing the bank's (Answer Man) to help them save money. The client loved the campaign and the male staff in our agency all supported the creative direction. It only made me anxious. 


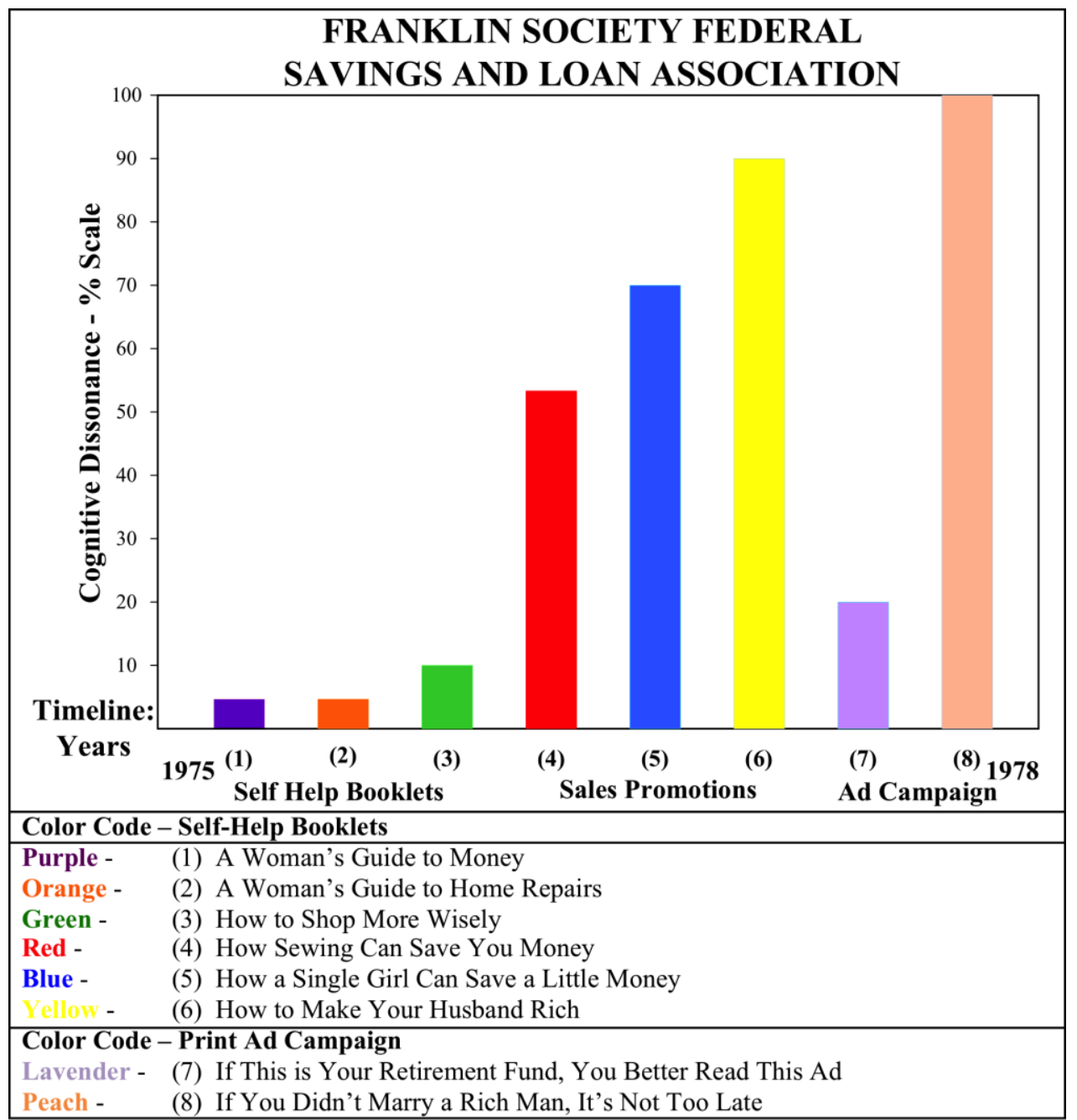

Figure 2: Changes in author's cognitive dissonance during Franklin Society Federal Savings and Loan Association Campaign

The ad campaign poignantly reflects a single woman's dilemma in a stagnant economy-the mid-1970s. It ran in The Daily News, The New York Post, The New York Times and Newsday. Targeted to working class planning for the future, the first ad displayed a large social security card with a headline suggesting: "IF THIS IS YOUR RETIREMENT FUND, YOU BETTER READ THIS AD." The second ad with a photograph of a smiling woman hugging her new fur coat close to her chest ran with the headline: "IF YOU DIDN'T MARRY A RICH MAN, IT'S NOT TOO LATE" (see Photo A). It was a time when tellers were female and officers were male, the ad prompts women needing guidance to talk to an Answer Man. Both ads end with branch addresses and the name of each Answer Man. The tag line double entendre "Our Interest Doesn't Stop With Your Money" reinforced an early example of relationship marketing. While other banks advertised the interest earned, Franklin's solution solved real problems with a customer-focused approach (Olsen 2009). The campaign was a success and raised the bank's value so that within two years it merged 
with a larger bank.

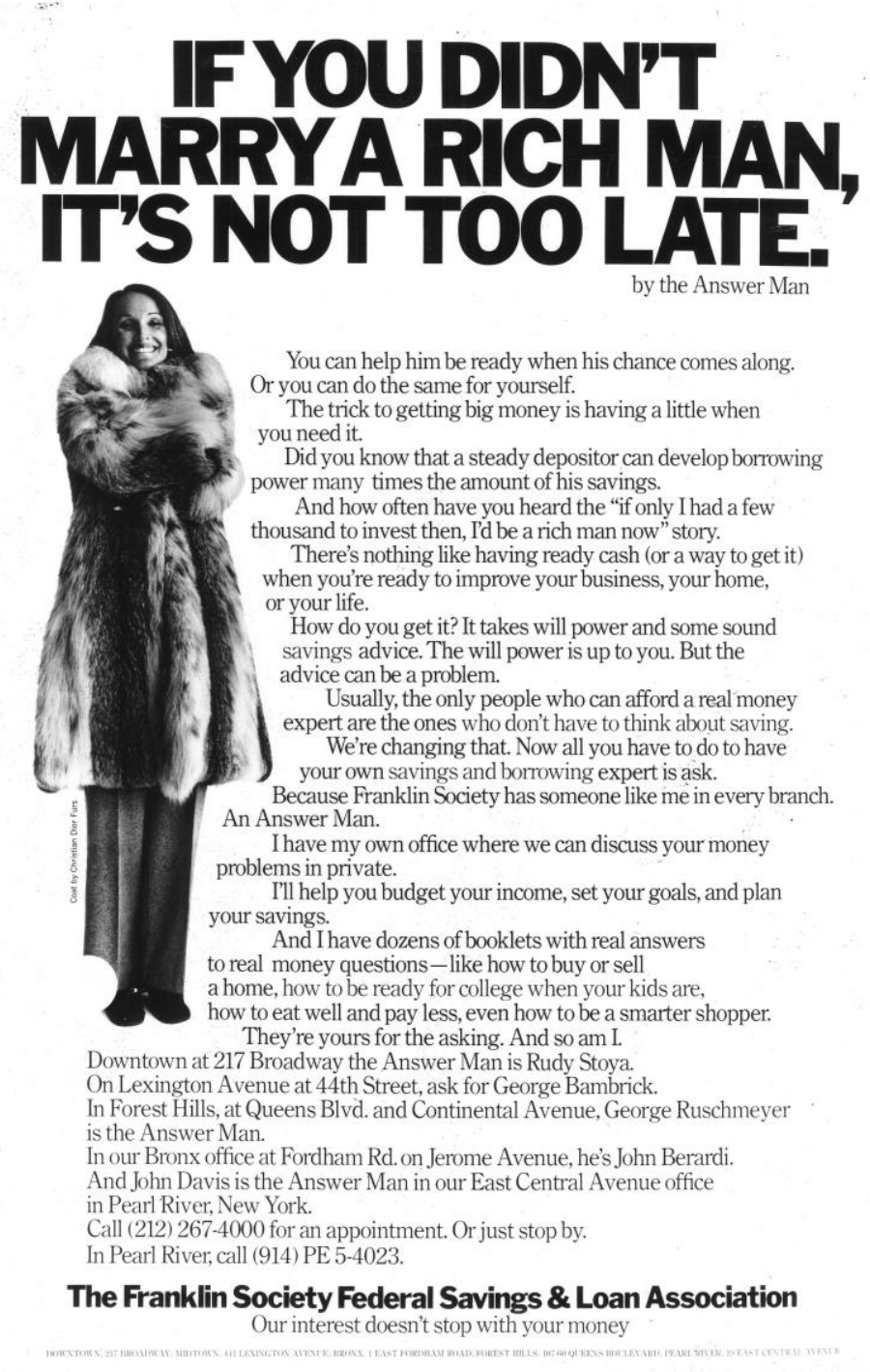

Photo A: Franklin Society Federal Savings and Loan Association print ad

\section{9 - Parochialism: ABC's Touch of Home ${ }^{\text {TM }}$}

In the late 1970s our agency worked with ABC Pictures International to promote their movies abroad. In 1978, they approached Adam with a proposal to market a new venture. Touch of Home would be sold by their Video Sales Division. The idea was to provide ABC network programming packaged on cassettes to U.S. multinational employees and their families living overseas. They found that repositioned families yearned for reconnection to stateside lives. With the product's international intent, Adam finally suggested I contribute anthropological input. As ABC created their own acculturation program and a monthly magazine, (similar to $T V$ Guide) called "Touch of Home Guide," there was little to add. However, I worked on the account as account executive. The agency produced an advertising campaign, the leave-behind (an abbreviated sales brochure given to prospective buyers) and a larger sales brochure. The campaign 
targeting corporate executives supported a practical idea to help employees (male) with wives and children stay happy for the duration of their overseas contract. The media plan included advertising in Time, Fortune, Forbes, U.S. News \& World Report, Newsweek, Business Week, The Wall Street Journal, and The New York Times. As a double-duty tactic, we used the ads as visuals in the brochures.

The first ad featured a happy family-mom, dad, son and daughter. It addressed the cost factor to send a family overseas with the headline: "It costs you over $\$ 200,000$ to send a family overseas. Now ABC helps make sure they stay." The copy followed:

You transferred four of your top people to four widely scattered locations around the world. And each brought a family who's been homesick since the day they arrived. It will take more than the usual bonuses, perks, allotments and allowances to make them happy. What they want is home.

... the same programming that's made ABC America's \#1 network....

The second ad, with visual reproduction of the "Touch of Home Weekly Program Guide," addressed the fact that an unhappy, bored family affects the productivity of the employee. This fear was relieved by the headline: "Now your overseas productivity problems can be solved in 48 hours." The copy concluded that, "A man who goes home to an unhappy family every night comes to work unhappy in the morning. And that can mean major productivity problems for you...." 


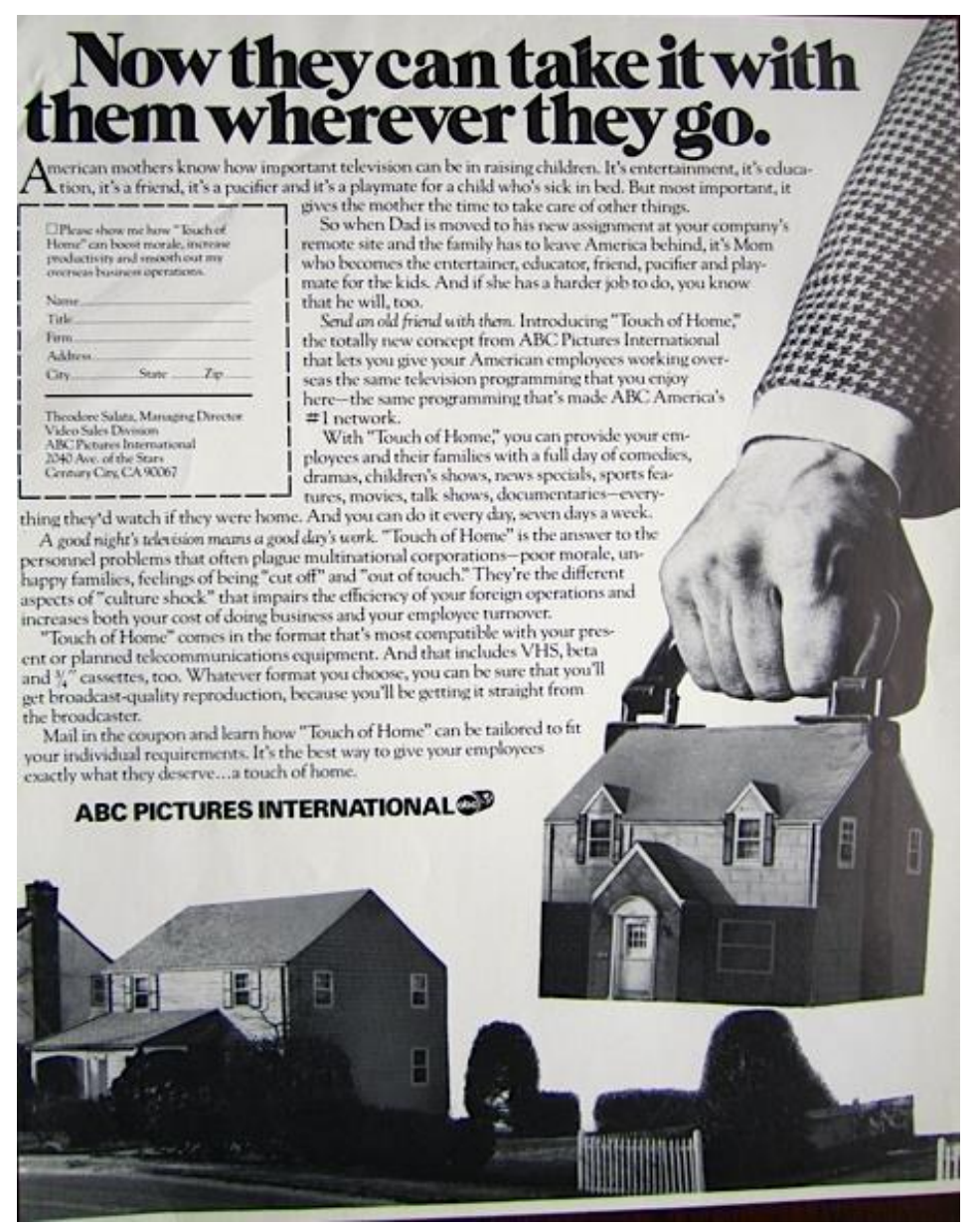

Photo B: ABC's Touch of Home print ad

The third ad (see Photo $B$ ) solves the problem by visually showing how the family can take their home with them on the sojourn abroad. The visual metaphor suggests that the resolution of homesickness is plugging in a cassette of $\mathrm{ABC}$ TV programming. The retouched photograph in the visual shows a businessman's hand clutching an attaché handle attached to the roof of his house as he lifts it off its suburban street. The headline saying "Now they can take it with them wherever they go," was followed by copy that Touch of Home was mother's helper, too:

American mothers know how important television can be in raising children. It's entertainment, it's education, it's a friend, it's a pacifier and it's a playmate for a child who's sick in bed. But most important, it gives the mother the time to take care of other things. And if she has a harder job to do, you know that he will, too.

A good night's television means a good day's work...

The effective and sadly true theme that families cannot live without TV as an entertainment pacifier critical for employee productivity continued through both brochures where we reproduced the ads for repetitive effect. Our Touch of Home sales brochure (1979:14) promoted “ABC's 
Family Orientation Service" that ABC produced in-house. It read:

Your employees and their families can begin adjusting to their new country overseas even before they leave the United States. Using both recorded and printed material in a total information package, they'll become acquainted with the people, the customs, traditions and the cuisine and learn the important words and phrases that they need to get started in their new country. It's the kind of orientation program that eases their transition through this difficult period of adjustment to life overseas and continues as long as they're there.

The end result was a brilliant campaign that addressed many complications faced by American employees and their families during overseas assignments. As will be elaborated on in the discussion section, I often discussed how the contradiction that American television programming delivered on video cassettes watched inside the home, perhaps all day, conflicted with the promise of easy acculturation initiated by $\mathrm{ABC}$ 's orientation program. Again, I was told to keep my concerns to myself, creating cognitive dissonance for me (see Figure 3). As can be seen on the graph, my cognitive dissonance scale was highest for this campaign because, as an anthropologist in graduate school, I was asked to contribute an opinion that was ignored. This campaign defied my anthropological belief that travel involves immersion in another culture. As part of my portfolio (along with the previous two campaigns) that I used to attract new clients, I wrestled with the Touch of Home concept during every sales pitch. 


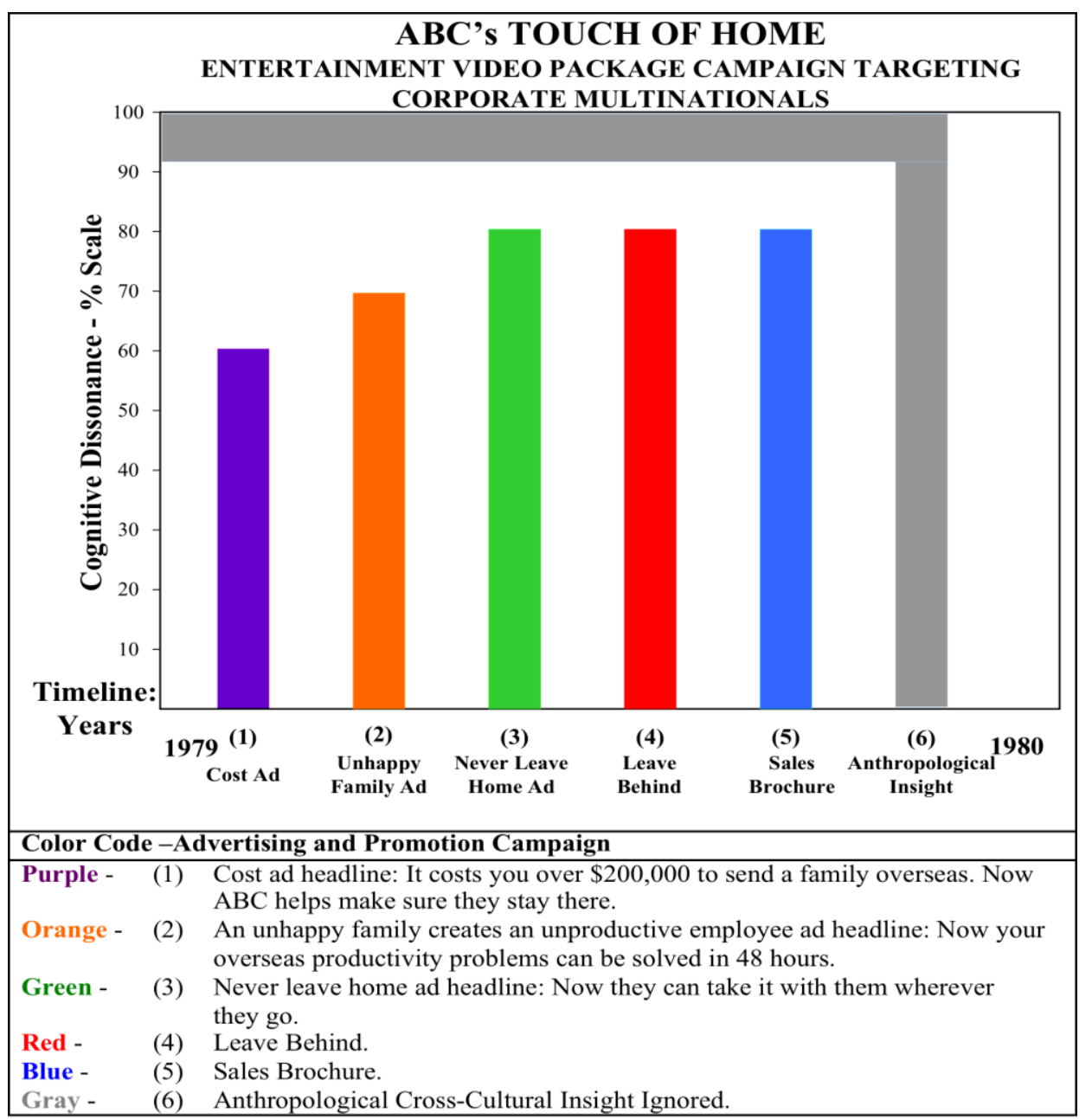

Figure 3: Changes in author's cognitive dissonance during $A B C$ 's Touch of Home Campaign

\section{Lessons from the log}

Reflecting on work performed is a chance to reexamine our own doubts, insecurities and troubled relationships. I found that corporate culture was historically contoured by socioeconomic dynamics which permeated positioning strategies and campaign themes. I was similar to many young women at the time reevaluating their own sexual mores and life ambitions experiencing various degrees of liminality.

From the beginning in 1972, I felt great ambivalence toward advertising as a career where anxiety ruled initiated by what I observed as a cult of the boss. In both Adam Wilson \& Friends and IMC, Adam as boss, was sole creative director and guru-hailed as invincible by all clients. "Many companies depend on a guru" (McCracken 2009:6) and all our clients considered Adam their guru to dispel the fear of uncertainty. In advertising, uncertainty exists everywhere: getting new business, executing campaigns, getting client approval, reaching deadlines, selling a product, and getting paid on time. 
Brownlie (1998:121) observes that, "uncertainty itself does not confer power, but rather coping with this uncertainty does..." and Adam was a master at manipulating uncertainty. To Adam, money was the salve to uncertainty. His primary policy above all was to make money, often using a heavy hand that came with human cost and great employee churn. My log reflects frustration with creative solutions and cruel management tactics coupled with survival strategies. As early as 1973, my log states:

Instinctively we know the good from the bad. There are two ways to reinforce behavior: Positively through setting an example and providing a reward [nurturing] healthy egos and strong relationships and Negatively, through authoritarian coercion and punishment producing intimidation and low self-esteem. Knowing why we do what we do is freedom (nd).

The agency culture I encountered was similar to Briody's discovery in GM manufacturing plants-it was a "blame" culture (2013:135-36). At Adam Wilson \& Friends, nobody-from the creative director-boss-guru to account executives, art directors, copywriters and traffic personnel (project tracker)-ever took responsibility for errors simply to avoid Adam's wrath. Most problems stemmed from inadequate communication between Adam and account executives and from them to copywriters and bullpen artists who took the brunt of the blame because doing the ad mechanicals twice pushed the limit of media deadlines. Friendly suggestions to remedy procedure only solicited further tirades.

My log repeatedly cites passages of frustration and remorse, as well as gaining incredible strength and fortitude. One cannot remain in a liminal state for too long without negative consequences. I came to realize that the contestation of wills was played out in part through eye control of the other's stare, so I learned to look at intimidators with my strong eye. "Between two people one of them will have a stronger eye muscle. That is the person who dominates the relationship" (Log, $5 / 2 / 74$ ). I discovered that if I returned the look with my strong eye, my attitude changed to confidence and I could not be bullied. A later passage notes, "The politics of intimidation is thought control" (Log 6/29/76). Across the industry, Adam was known for having a tyrannical personality and for being hard to work for, which accounted for the employee churn. By 1979, in total frustration, I wrote, "For years I couldn't find the words and now I cannot find the voice. At least my pen still flows. [My] drawings are diagrams of the heart" (Log 1/23/79).

While I found release in drawing and philosophizing in my log, some events were harder to process with a participant-observer distance. An account executive stole $\$ 200,000$ from the Adam Wilson \& Friends agency. In addition, the log continued that we had another crisis when our production manager (Steve) created a shadow company to siphon funds away from the agency. I wrote in my log, 
Unbeknownst to Adam or me, Steve formed a separate company called Scanagraphics from which he billed the clients for jobs done by other companies ... He bragged [to a secretary] at having stolen $\$ 75,000$ through obtaining our commissions from media and from kickbacks. He took the money to the Bahamas... What can come from swimming with this tide? (November 1979 nd)

It was a time for survival, not only for the agency, but also, I saw an opportunity to find greater autonomy by starting a sister agency, IMC Marketing Group with Adam as creative director. I did not hire thieves. However, I soon observed:

This is a journal of frustration. I'm writing because I can no longer continue working in advertising without a critical perspective, without some kind of divorce from reality. If I can survive as a participant-observer of my daily experience, perhaps then I may maintain both my sanity and my job (Log, 10/20/80).

A week later the reflection continues with my understanding that the most used phrase in the business is "Cover Your Ass." I wanted to leave, but felt a personal responsibility to the agency and to Adam. This is when my log becomes a purposeful tool for protection against lies and broken promises. "Uncertainty and confusion encourage us to make insightful connections in apparent disunity and see what we might not normally see" (Malefyt and Morais 2012:84). My detour now had a clear purpose to use my time to work on advertising accounts with clear focus to earn the Ph.D. in anthropology.

\section{Discussion: Critical introspection with implications and lessons for practitioners}

This critical analysis of the three campaign cases juxtaposed against survival strategies in a dysfunctional corporate culture has relevance for practicing anthropologists when negotiating their own emotional labor. Survival strategies as lessons learned during the field experience include the application of anthropological methods: participant observation, maintaining detailed introspective field notes, and a longitudinal approach which, years later, allows a reflexive critical examination of the campaign archives.

Many insights emerged from this process. They align with recent research in consumer behavior and marketing literature advocating introspection and a critical perspective. Gould (2008:311-312) notes that "while researchers sometimes recognize the personal subjectivity present in their own critical practices, they nonetheless do not fully reflect about it introspectively or integrate it in a way that demonstrates how it informs their work." He writes extensively on introspection with 
practical advice to perfect this methodology. He continues, "I argue that introspection concerning one's subjectivity is a key, if not the key to the construction and comprehension of critical thought (i.e., authors write and readers read in ways that are both self-and culturally embedded)" (p.313). While analyzing the cases presented, I realize that I never viewed marketing products through the lens of the marketer, but instead focused on product meaning for consumers buying the products. Following the critical marketing paradigm (Saren et al. 2007; Tadajewski and Brownlie 2008), O'Shaughnessy advocates that researchers use "ethnospsychology as the study of folk psychology" to understand "consumer actions from the consumer's point of view (2008:158).

Considering the neophyte role mentored by a guru, one reviewer noted that mentoring is similar to the shamanic quest with incorporation of a new identity at journey's end. However, my guru, while ahead of the marketing curve, often proselytized antiquated social values. Since I was part of the team that used our clients' campaigns to get new business, each case was problematic: Warner's Bra objectified women; Franklin Society Federal Savings and Loan Association's promulgated women's financial independence while deferring a paternalistic authority to men; and the $\mathrm{ABC}$ Touch of Home video package containing American ethnocentric focused entertainment for multinational employees' families, violated my anthropological imperative for cultural immersion. During the execution of the campaigns, my intuition told me that many parts of our creative direction were in poor taste and socially incorrect. In this reflective narrative, I have used the trope of cognitive dissonance with graphs to visually explain this intuitive logic. In the following section where I critically dissect client ads and sales promotions, Figures 1-3 visually demonstrate the level of cognitive dissonance I experienced with each project.

\section{The Warner's Bra campaign}

The Warner's Bra sales promotion and advertising campaign was my introduction to advertising. As a freelance artist, I became familiar with the campaign that led to the brilliant strategy that changed the entire industry. I was smitten by the excitement and limitless expense accounts that allowed us to entertain clients at the finest midtown restaurants. Adam even had his favorite table at the Laurent Restaurant where he and I usually had dinner, opposite Salvador Dali and his wife, Gala's table, when they came to New York and stayed at the Lombardy Hotel upstairs. It was a schizophrenic life between day and night, work and weekend.

A neophyte in training at the agency, I worked primarily in the art department. Adam promoted favored employees quickly to new positions and welcomed all opinions for creative inspiration. I was filled with good ideas and rarely held my tongue even when advised not to speak. As Figure 1 shows, my participant observation came with 
escalating liminality or cognitive dissonance. I was new to the industry and Warner's Bra was my first exposure to the licentious logic that sex sells more than bland reason-why positioning. While enjoying the freedom of the 1960's-inspired sexual revolution, I was socially conditioned to be a prude (Olsen 2006:175). I was shocked by the Warner's campaign.

The sales promotions registered on my cognitive dissonance barometer between 30 and 80 percent. Adam's condemnation of my anthropological contribution that continued throughout my tenure topped the scale. The horoscope readings, birthday cards and Easter flowers were the most benign. At the time, those dabbling in astrology often wrote horoscope charts for friends. "Love is in the Palm of Your Hand" included a rendering of palm lines on clear acetate predicted a customer's future. The acetate said, "Your Future is a Present From "Love Touch' By Warner's." It seems contrived and trivial. The consumer booklet "50 ways to please your lover" was more difficult for me to connect with because it cast women as sex objects needing instruction to compliment, pleasure, and keep their lovers satisfied. Most women at the agency were embarrassed by it. It was the only promotion that was lost to posterity due to its popularity with men. All samples vanished by the 1980s. The Christmas recipe book "Guide to holiday shortcuts for tired sales girls" stereotyped female clerks as "girls" rather than acknowledging them as women performing a critical job. It would be a long time before service workers became respected "sales associates." The booklet has a cover photograph showing an exhausted, middle-aged woman at home sinking into her easy chair. She is incredibly disheveled. Her mouth is turned into a frown and a message is pinned to her blouse saying, "May I help you"? Yes, this woman clearly needed a reward for being overworked in the lingerie department. It was a time of staff cut backs in all retail stores. The message demonstrated that Warner's sympathized with her situation. However, it seems ingenuous to assume she was ready to cook, bake, and make intricate drinks to entertain guests at a Christmas party. She needed a rest!

Every time I produced these promotions to tell the campaign story, I gagged on the presentation while also remembering Adam's protestation to keep my opinions to myself. Early on, I realized this career would not be an easy fit. But I loved the creativity and looked forward to new accounts with creative challenges.

\section{Franklin Society Federal Savings and Loan Association}

The Franklin bank campaign targeted the vulnerable working class and women experiencing liminal economic insecurity. It resonated a high level of cognitive dissonance. At the time I was in my own liminal zone after divorce and particularly sensitive to the advertising and

promotional booklet copy. During a conversation with him in 2002, he 
admitted using my experience to target financially insecure women.

As the assistant on the account, I realized I could benefit from advice in the first three booklets (see Figure 2). The sixth, "How to Make Your Husband Rich," was particularly irksome because my ex had left me for a wealthier woman and never had to work again. I resisted the notion that Franklin could help me "save money" by sewing! Ironically, it was Adam who benefitted from my sewing and my being between work and school; I had little time to sew. I resented the fifth booklet "How a Single Girl Can Save a Little Money," because I was in graduate school and well educated, yet was paid less than my less educated male peers. Most workers in entry-level positions had too little income to save.

The first ad featured a Social Security card, paired with advice not to rely on it for retirement. The visual and headline captured attention with a call to the obvious and stigmatized the truly impoverished unable to save. The second ad with a woman in fur coat, said "If you didn't marry a rich man, it's not too late." It played on a common theme that women marry for money. All we needed was a bank account as surrogate for a man's support and an Answer Man for help. I hated the creative direction. My advice suggesting a more progressive campaign positioning a stronger female using her savings to fulfill her potential fell on deaf ears. Adam convinced the client his ideas would produce results and they did. In conclusion, the strategy raised Franklin's market share enough so that it merged with a larger bank. I used the Franklin campaign to solicit banking clients in the 1980s.

\section{$A B C$ 's Touch of Home}

For ABC's Touch of Home, an anthropological perspective was appreciated and voiced in their in-house Orientation Program. The intent was to keep the family happy and the employee productive. It was a rare opportunity for a marketing anthropologist in the role of account executive. Unfortunately, the results isolated families from experiencing local culture (see Figure 3). The brochures we produced were intended to convince multinational corporate executives why overseas employees needed daily American television that satellite transmission at the time was incapable of delivering. The Touch of Home sales brochure (1979) suggests that everyone's happiness depends on familiar TV viewing because "television has become a cornerstone of the American lifestyle" (p.9). The campaign direction empathized with the expatriate condition of "disorientation and boredom," to which an anthropologist might suggest taking a walk to experience local culture and make new friends.

Upon reflection, I think the account was perfect for an anthropology student immersed in the language of liminality from van Gennep (1960) and Turner (1969), who was studying liminal people in transition. Our campaign eased the problem for dislocated families who 
played a critical role in employee productivity. Expatriate spouses and families experience their own liminality accompanying husbands and fathers overseas. Briody and Chrisman conducted in-depth research on the acculturation experiences of General Motors' expatriate employees and their families adapting to new locations when posted abroad. Similar to the problem that $\mathrm{ABC}$ was trying to solve, they found that the employees (all were male) could integrate more easily because work absorbed most of their time. Briody and Chrisman (1991) found that adjustment was more problematic for the spouses (all were female), because filling time "related to their relatively unstructured daily schedule and their lack of social networks, particularly at the outset of overseas assignment" (p.268). In one interview, an employee sympathized with his wife and children, because they "had hours and hours in which they had to face the unknown'” (p.267). ABC's Touch of Home campaign addressed this "unknown" by turning attention to the importance of keeping the family entertained.

My conflict with Touch of Home reached a new level of cognitive dissonance. Cultural exposure and acculturation should have meant a joyful immersion in another life experience during their assignment. TV programs from home seemingly aborted a perfect opportunity to establish cross-cultural friendships and memories. Again, I acquiesced my cultural sensitivity to a client's product needs. With satellite transmission of programming on the horizon, American television syndicators soon supplied the global marketplace. Adam Wilson \& Friends joined this process, producing sales brochures and ads for our syndicators selling abroad. Refuge came with my intensified focus on anthropology and on illustrating The Way of the Shaman for Michael Harner (1980), who became my thesis advisor, with Shirley Lindenbaum and William Roseberry joining my committee.

\section{Conclusion}

Absorbed by the advertising world in a state of liminality, my perspective was incongruent with agency mores. Moeran (2014:4) suggests that scholars should continue to critique and "problematize the taken-forgranted, ... [and be] not afraid to criticize, on the basis of their extended research, business forms and practices they deem to be unethical or morally reprehensible." In retrospect, it was a dysfunctional workplace because of the "conflation of boss and company" (Carrier 2013:122). I didn't realize how dysfunctional the agency had become until rereading my log, which has more to say about personnel chaos than account management. Many problems, unfortunately, stemmed from the arrogance of the boss-creative director's personality. Employees feared his intimidation and tantrums. However, I shared our clients' admiration for his marketing knowledge and creative solutions. Indeed, few knew the quiet side of Adam. He was kind and considerate and loyal to the few 
friends he had. As a single father, he was devoted to his sons. Most of his down time was spent at museums with his sons or home painting at his easel, reading, studying military history, and painting toy soldiers he bought to add to his vast collection.

Adam was the creative guru of the agency and the mastermind of each campaign theme that empowered target markets. Even on weekends, Adam never stopped working. He used every opportunity to observe people in his quest for cultural knowledge that could be converted into campaign solutions that satisfied customers. The Warner's and Franklin Bank campaigns were a testament to his perception that the 1970s were a time when many women were experiencing their own liminal passage to sexual and financial independence. Marketers assist in such transitions by providing products for identity play. Our sexualized campaign theme to sell bras paralleled the sexual revolution of the 1960s and 1970s. Warner's Bra empowered women by providing consumer choice in retail stores using the "open merchandising concept" (Olsen 2003:127). This change in practice stimulated competition in the category that continues unabated today. Our agency's effort was a revolution for lingerie that precipitated a cultural turn in the marketplace. With the Love Touch sales promotion and advertising campaign, our agency participated in the feedback loop by which social mores and cultural attitudes were transformed.

Similarly, the Franklin Society Federal Savings and Loan campaign reflects socioeconomic dynamics that drew young women to college and into the work force during the 1960s and 1970s. By providing the fatherly figure of an Answer Man with emotionally charged ads and condescending self-help booklets, the campaign took a paternal interest in the single woman's need for practical advice to save money.

Touch of Home solved a productivity problem for American corporations expanding abroad by shipping favorite television shows on cassettes to their employees and their families overseas. As previously noted, the acculturation problem for spouses and children was more problematic than for the male employees. The unhappy family was a window of opportunity for our client ABC Pictures International and an inspiration for our agency's campaign theme. The metaphorical home was their TV set; ABC's network programming became the home companion for nostalgic families not comfortable in their foreign environment. From my perspective, the product isolated families from the host culture while the campaign pandered to a parochial niche dependent on American television shows. However, by adopting the program, each family had more control over their daily circumstances.

The campaign themes followed the academic marketing dictum to satisfy the wants and needs of target markets. This does not suggest that all creative solutions were executed with optimal consideration for sociopolitical correctness. These three campaigns, as demonstrated by 
the three Figures, prompted a series of liminal dilemmas for me.

The cognitive dissonance began when I worked freelance in the agency on Warner's campaign before joining full time in 1972. At a meeting sometime in 1971, I offered a suggestion to use anthropological participant observation with bra customers that was rebuffed by Adam. It was the first time I felt like I did not belong. Every subsequent suggestion using anthropological insight prompted Adam to respond with variations on the theme, "Leave your anthropology at school." His antipathy to my anthropology was numbing. I persisted with opinionated judgment calls whenever I thought his creative direction warranted oversight. While my freelance role with the agency was with the art department, during 1971 I sporadically observed the evolution of the Love Touch bra campaign that continued after I joined full time. My initial reaction to the trade ads was benign. The liminal point of separation started when I began to distance myself from the love and sex creative direction while working on art renderings in the bullpen. By the end of 1972, I realized that sex was a prevailing advertising solution to break through the clutter to get noticed. During my transition phase, I developed a thicker skin and relaxed my prudishness. The media, magazines, television, movies and even fashion, promoting the mini skirt, were exuding sexuality as they percolated through a changing culture. With incorporation, I recognized that the campaign was characteristic of the era in which it evolved by symbolizing women in their lingerie as sex objects. I professionalized my feelings and swallowed my pride, determined to continue working toward my Ph.D.

During the Franklin bank campaign, I was more actively involved as assistant account executive engaging in bank observations and client meetings as well as interacting with the art department. Figure 2 reveals a slower emergence of cognitive dissonance that escalated dramatically. The liminal process began when the booklets became personal. I liked to sew, I needed to save my money, but I definitely did not want to make a husband rich. Separation was immediate and visceral. The campaign made me sick. The advertisements made me realize I needed a career I could contribute to for a lifetime and not marry again for a very long time. I was strengthened through the transition by drawing in my log. There are pictures of powerful, earth mother females pregnant with the earth (as seen from outer space) floating in their wombs. I used my dominant eye to focus on other eyes in conversations with Adam, clients and employees. This helped strengthen my resolve not to capitulate. I felt personally empowered as I came through this passage. By 1977, incorporation was complete with a different sense of my Self. I was strong enough to say goodbye to my personal relationship with Adam and empowered by my conviction I would earn my Ph.D. while still working with him. This was the most powerful personal experience of liminality during my career because it was so personal. 
Touch of Home, on the other hand, represented a professional contestation of wills. The client had a product that it believed solved an all-too-real corporate dilemma. Adam had a creative solution that satisfied the problem while I had my own anthropological agenda. Because I was now fully committed to my anthropology curriculum, the Touch of Home program made no sense to me. The separation phase began. As a marketing account executive, it solved family homesickness and raised employee productivity to a degree. As soon as I got the account, I began to pull away, cognitively separating marketing from anthropology. I was truly "betwixt and between." As we executed the campaign, my protestation was ignored, but I was in transition with a plan. My role on the account was keeping records, getting client approval and making sure that the copy and art proceeded in a timely manner to meet due dates. Ultimately, it led to my incorporation phase. I incorporated a new professional identity that coincided with a major disruption in the agency mandating a timely separation of accounts. I also incorporated IMC with the hope that the future agency would be more manageable under the rubric that Adam, theoretically, would be working for me. In my experience, these three campaigns suggest that the liminal zone and passage can be a learning experience. When consciously applied for personal empowerment, the process can be life changing.

This article has implications for anthropological training and practice because it demonstrates how different methodologies can be used for insight and reflection. It critically probes marketing practice using traditional anthropological methods; participant-observation, field site journal notes and longitudinal analysis. By presenting the campaign cases from the perspective of the participant in the marketing practice, I connect introspection of cognitive dissonance in a reflexive retrospection and suggested these strategies for surviving liminal conflict (zones). Thus, this article presents a multi-technique methodology for the practicing anthropologist's toolbox.

Sunderland and Denny (2003:192) suggest that as investigative anthropologists "we are generally listening and looking for the "invisible' cultural meanings and categories that organize people's perceptions and actions." From the Mad Men era of the 1970s with Warner's Bra, Franklin Society Federal Savings and Loan Association to ABC Picture's Touch of Home, clients offered products as cultural solutions that solved real problems initiated by historical circumstances. Their campaigns and my field notes helped pry open "the invisible" to understand how liminality appeared within this time frame and how I learned to cope with and overcome the imbalances of gender, class and moral issues.

\section{Acknowledgments}

The author thanks the reviewers for their wise suggestions, Maryann McCabe for inspirational advice, Antonella Fabri for her close reading of 
an earlier draft, and Costas Hadjicharalambous for his part in preparing the figures. My deepest gratitude extends to Elizabeth Briody for her patient diligence editing this paper.

\section{References}

Arnould, E.J. and C. Thompson. 2005. Consumer culture theory (CCT): Twenty years of research. Journal of Consumer Research 31: 868-882.

Beech, N. 2011. Liminality and the practices of identity reconstruction. Human Relations 64(2): 285-302.

Briody, E.K. and J.B. Chrisman. 1991. Cultural adaption on overseas assignments. Human Organization 50(3): 264-280.

Briody, E.K. 2013. Collaboration and anthropology in corporate work. Journal of Business Anthropology 2(2): 133-167.

Brownlie, D. 1998. High minds and low deeds: On being blind to creativity in strategic marketing. Journal of Strategic Marketing 6: 117130.

Carrier, J.G. 2013. Business literature and understandings of business. Journal of Business Anthropology 2(2): 120-132.

Cracknell, A. 2011. The real mad men: The renegades of Madison Avenue and the golden age of advertising. Philadelphia, PA: Running Press.

Gould, S.J. 2008. Introspection as critical marketing thought, critical marketing thought as introspection. In Critical marketing: Issues in contemporary marketing. M. Tadajewski and D. Brownlie, eds. Chichester, West Sussex, UK: John Wiley \& Sons, 311-328.

Hackley, C. 2002. The panoptic role of advertising agencies in the production of consumer culture. Consumption, Markets and Culture 5(3): 211-229.

Harner, M. 1980. The way of the shaman. New York, NY: Harper and Row Publishers.

Hodder, I. 2012. Entangled: An archaeology of the relationships between humans and things. Chichester, West Sussex, UK: John Wiley and Sons.

Kaminsky, M. 1992. Introduction. In Remembered lives: The work of ritual, storytelling and growing older. B. Myerhoff. Ann Arbor, MI: The University of Michigan Press.

Maas, J. 2012. Mad women: The other side of life on Madison Avenue in the 60s and beyond. New York, NY: Thomas Dunne Books, St. Martin's Press.

Malefyt, T. de Waal and R.J. Morais. 2012. Advertising and anthropology: Ethnographic practice and cultural perspectives. New York, NY: Berg. 
Marcus, G.E. and M.M.J. Fischer. 1986. Anthropology as cultural critique: An experimental moment in the human sciences. Chicago, IL: University of Chicago Press.

McCracken, G. 2009. Chief culture officer: How to create a living, breathing corporation. New York, NY: Basic Books.

Moeran, B. 2014. Changes and continuities: A revised strategy for the JBA. Journal of Business Anthropology 3(1): 1-4.

Olsen, B. 2003. The revolution in marketing intimate apparel: A narrative ethnography. In Advertising cultures. T. de Waal Malefyt, and B. Moeran, eds. New York, NY: Berg, 113-138.

Olsen, B. 2006. Understanding my life: The dialectics of marketing and anthropology. In Women in anthropology: Autobiographical narratives and social history. M.G. Cattell and M.M. Schweitzer, eds. Walnut Creek, CA: Left Coast Press, 173-182.

Olsen, B. 2009. Rethinking marketing's evolutionary paradigm and advertisers' role as cultural intermediary. In Explorations in consumer culture theory. J.F. Sherry, Jr. and E. Fischer, eds. New York, NY: Routledge, 57-82.

O’Shaughnessy, J. 2008. Ethnopsychology: A return to reason in consumer behavior. In Critical marketing: Issues in contemporary marketing. M. Tadajewski and D. Brownlie, eds. Chichester, West Sussex, UK: John Wiley and Sons, 157-182.

Saren, M., P. Maclaran, C. Goulding, R. Elliott, A. Shankar and M. Catterall, eds. 2007. Critical marketing: Defining the field. Oxford, UK: Butterworth-Heinemann.

Schouten, J.W. 1991. Personal rites of passage and reconstruction of self. NA - Advances in Consumer Research. 18, R.H. Holman and M.R. Solomon, eds. Provo, UT: Assoc. for Consumer Research: 49-51.

Sunderland, P.L. and R.M. Denny. 2003. Psychology vs.

Anthropology: Where is Culture in Marketplace Ethnography? In Advertising Cultures. T. de Waal Malefyt and R.J. Morais, eds. New York, NY: Berg: 187-202.

Tadajewski, M. and D. Brownlie, eds. 2008. Critical marketing: Issues in contemporary marketing. Chichester, West Sussex, UK: John Wiley \& Sons.

Tempest, S. and K. Starkey. 2004. The effects of liminality on individual and organizational learning. Organization Studies 25(4): 507-527.

Touch of Home ${ }^{\mathrm{TM}}$. 1979. Sales brochure. ABC Pictures International; ABC Video Sales Division.

Turner, V. 1969. The ritual process: Structure and anti-structure. New York, NY: Aldine. 
Turner, V. 1979. Betwixt and between: The liminal period in rites de passage. In Reader in comparative religion: An anthropological approach. W.A. Lessa and E.Z. Vogt, eds. New York, NY: Harper and Row Publishers, 234-243.

van Gennep, A. 1960. The Rites of Passage. Translated by M.B. Vizedom and G.L. Caffee. Chicago, IL: University of Chicago Press.

Barbara Olsen, Ph.D. is Professor of Marketing in the State University of New York at Old Westbury where she has taught consumer behavior, branding and marketing courses for 27 years. She obtained her Ph.D. in anthropology from the New School for Social Research while building a career in advertising. Her current research interests explore the sociocultural dimension of consumption and consumer engagement with art, music and lifestyle choices. Her articles have appeared in the Journal of Business Research, Consumption Markets and Culture, and Human Organization, and as chapters in numerous books. She may be contacted at olsenb@oldwestbury.edu 